ISSN 1420-3049

http://www.mdpi.org

\title{
Synthesis of Camalexin
}

\author{
M. Dzurilla*1 ${ }^{1}$, P. Kutschy ${ }^{1}$, J. Zaletova ${ }^{1}$, M. Ruzinsky ${ }^{1}$ and V. Kovacik ${ }^{2}$ \\ ${ }^{1}$ Department of Organic Chemistry, Faculty of Natural Sciences, P.J. Šafárik University, \\ Moyzesova 11, 04167 Košice, Slovak Republic. \\ E-mail: dzurilla@kosice.upjs.sk, kutschy@kosice.upjs.sk, zaletova@pobox.sk \\ 2 Institute of chemistry, Slovak Academy of Sciences, Dúbravská cesta 9, 84238 Bratislava, \\ Slovak Republic. E-mail: chemvkov@savba.sk
}

*Author to whom correspondence should be addressed; E-mail: dzurilla@kosice.upjs.sk

Received: 6 April 2001; in revised form 13 August 2001 / Accepted: 14 August 2001 / Published: 31 August 2001

\begin{abstract}
In this paper we describe a new method for the synthesis of camalexin (1) based on the reaction of 1-(tert-butoxycarbonyl)indole-3-carboxaldehyde with methyl Lcysteinate hydrochloride, followed by oxidation and decarboxylation. Compounds $\mathbf{1}$, and intermediates 5-7 were identified by elemental analysis, ${ }^{1} \mathrm{H} \mathrm{NMR},{ }^{13} \mathrm{C}$ NMR and mass spectroscopy.
\end{abstract}

Keywords: Camalexin, phytoalexins, indoles

\section{Introduction}

Camalexin [3-(2'-thiazolyl)indole] (1) is a natural phytoalexin, isolated for the first time from the leaves of Camelina sativa and elicited by the fungus Alternaria brassicae [1]. Camalexin is also the principal phytoalexin found in Arabidopsis thaliana [2]. It exhibits antifungal activity similar to the systemic fungicide thiabendazole (2) [1,3] and also has antitumor activity [4]. In the literature there are described four methods for synthesis of camalexin, based on the reaction of indolylmagnesium iodide with 2-bromothiazole [3], heating of indole-3-carboxamide with $\mathrm{P}_{2} \mathrm{~S}_{5}$ and chloroacetaldehyde diethyl acetal in ethanol [5], reductive cyclization of 2-formamidophenyl-2'-thiazolylketone upon heating with 
$\mathrm{TiCl}_{3}$ and zinc dust [6] and reaction of 1-sulfonyl-3-iodoindole with active zinc and following Pd catalyzed arylation with 2-iodothiazole [7]. Recently, it has been suggested that the biosynthesis of camalexin involves the condensation of indole-3-carboxaldehyde with cysteine followed by a two-step oxidation and decarboxylation [8,9]. In the presence work we have studied the synthesis of camalexin according to this biosynthetic scheme.<smiles>c1ccc2c(-c3nccs3)c[nH]c2c1</smiles>

Camalexin 1<smiles>c1ccc2[nH]c(-c3cscn3)nc2c1</smiles>

Thiabendazole 2

\section{Results and Discussion}

As the first step in the investigated synthesis of camalexin, we have examined the cyclocondensation of indole-3-carboxaldehyde with methyl L-cysteinate. The product of this reaction appeared to be unstable and therefore it was decided to use the 1-Boc protected aldehyde 3. The cyclocondensation of 1-(tert-butoxycarbonyl)indole-3-carboxaldehyde with methyl L-cysteinate (4) hydrochloride afforded $4{ }^{\prime}$-methoxycarbonyl-1-(tert-butoxycarbonyl)-3-thiazolidine-2' - -yl)indole (5) as a mixture of diastereoisomeres in $85 \%$ yield (Scheme 1). The ratio of diastereoisomers was determined to be $57: 43$ by integration of the signals of proton $\mathrm{H}-2^{\prime}$ at $\delta=5,78$ and $6,01 \mathrm{ppm}$ in the ${ }^{1} \mathrm{H}-\mathrm{NMR}$ spectrum of the crude product.

\section{Scheme 1}

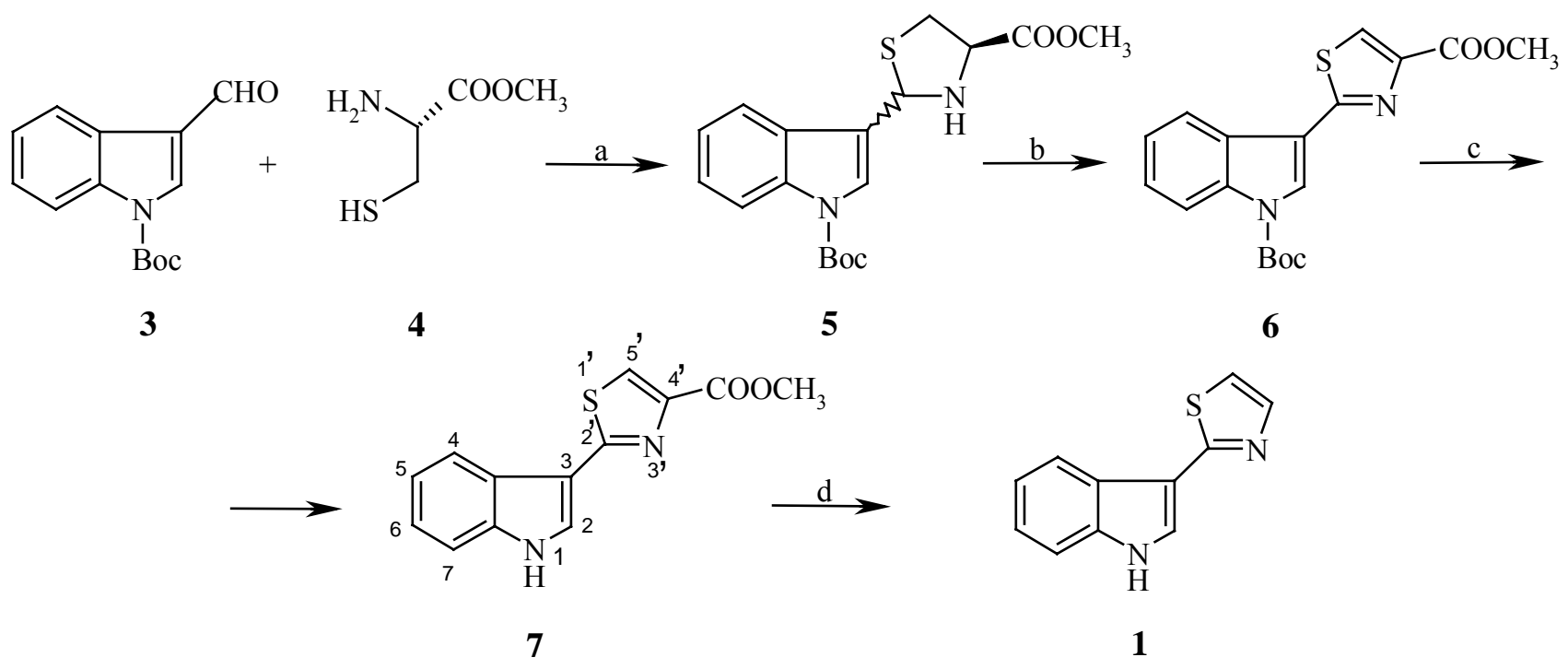

a) 1:2 methanol/benzene, $\left(\mathrm{C}_{2} \mathrm{H}_{5}\right)_{3} \mathrm{~N}, 25^{\circ} \mathrm{C}, 3 \mathrm{~h}$. (85\%); b) $\mathrm{MnO}_{2}$, benzene/pyridine, $55^{\circ} \mathrm{C}, 1.5 \mathrm{~h}$., (44\%); c) $\mathrm{CH}_{3} \mathrm{ONa}$, methanol, $25^{\circ} \mathrm{C}, 20 \mathrm{~min} .(59 \%)$; d) $\mathrm{NaOH}, \mathrm{NaHCO}_{3}, 25^{\circ} \mathrm{C}, 2$ h., (12\%). 
Oxidation of thiazolidine 5 to thiazole 6 by oxidizing reagents such as pyridinium chlorochromate (PCC), p-chloranil, 2,3-dichloro-5,6-dicyano-p-benzochinone (DDQ) and $\mathrm{FeCl}_{3}$ lead to decomposition products. The desired oxidation was achived by using 25 equivalents of activated $\mathrm{MnO}_{2}$ in dry benzene [10]. Elimination of the tert-butoxycarbonyl protective group was realized using 16 equivalents of sodium methoxide in methanol at ambient temperature. Subsequent hydrolysis and decarboxylation of the resulting 4'-methoxycarbonyl-3-(thiazole-2'-yl)indole (7) with an aqueous solution of $\mathrm{NaOH}$ and $\mathrm{NaHCO}_{3}$ gave camalexin (1) in $12 \%$ yield. The spectral data and melting point of $\mathbf{1}$ are identical with the literature data $[1,3,6]$.

\section{Conclusions}

In this contribution we report a biomimethic synthesis of camalexin (1) according to the proposed biosynthetic scheme. The formation of the thiazole ring involves only one oxidation step followed by decarboxylation to camalexin.

\section{Acknowledgments}

We thank the Grant Agency for Science of the Slovak Republic (grant No. 1/6080/99) for financial support of this work.

\section{Experimental}

\section{General}

Melting points were measured on a Koffler hot stage apparatus and are uncorrected. Purity of compounds was confirmed by elemental analysis on a Perkin-Elmer, model 2400 analyzer. The reaction course was monitored by TLC on Silufol (Kavalier) and Alumina $60 \mathrm{~F} 254$ neutral (Merck) TLC plates. Preparative column chromatography was performed on Kavalier 40/100 $\mu \mathrm{m}$ silica gel and Merck Kieselgel 60 F25. The infrared absorption spectra of compounds 1, and 5-7 were measured in $\mathrm{CHCl}_{3}$ on an IR75 (Zeiss Jena) spectrometer in the region $400-4000 \mathrm{~cm}^{-1}$. The ${ }^{1} \mathrm{H}-\mathrm{NMR}$ spectrum of 5 was measured on a TESLA BS $487 \mathrm{~A}(80 \mathrm{MHz}),{ }^{1} \mathrm{H}$ - and ${ }^{13} \mathrm{C}-\mathrm{NMR}$ spectra of compounds $\mathbf{1 ,} 6,7$ on a Varian Gemini 2000 (300 MHz)_in deuterochloroform, using tetramethylsilane as an internal standard. The electron impact mass spectra of 7 were recorded on a Finnigan SSQ 700 spectrometer at an ionization energy of $70 \mathrm{eV}$. Methyl L-cysteinate hydrochloride, pyridinium chlorochromate (PCC), pchloranil and 2,3-dichloro-5,6-dicyano-p-benzoquinone (DDQ) from Fluka, Merck and Avocado were used as obtained without further purification. 1-(tert-Butoxycarbonyl)indole-3-carboxaldehyde (3) was prepared according to the described procedure [11]. 
1-(tert-Butoxycarbonyl)-4'-methoxycarbonyl-3-(thiazolidin-2'-yl)indole (5).

To a suspension of methyl L-cysteinate hydrochloride $(595 \mathrm{mg}, 3.47 \mathrm{mmol})$ in $1: 2$ methanol/benzene $(6 \mathrm{~mL})$ was added 1-(tert-butoxycarbonyl)indole-3-carboxaldehyde (490 mg, 2 $\mathrm{mmol})$ and triethylamine $(672 \mathrm{mg}, 6.6 \mathrm{mmol})$. The reaction mixture was stirred for 3 hours at room temperature, the solvent was evaporated and the oily residue purified by column chromatography, using a mixture of cyclohexane/acetone (2:1) as eluent. Yield $615 \mathrm{mg}(85 \%)$, yellow oil; For $\mathrm{C}_{18} \mathrm{H}_{22} \mathrm{~N}_{2} \mathrm{O}_{4} \mathrm{~S}$ (362.50) calculated: $59.65 \% \mathrm{C}, 6.12 \% \mathrm{H}, 7.73 \% \mathrm{~N}$; found: $59.60 \% \mathrm{C}, 6.07 \% \mathrm{H}, 7.65 \% \mathrm{~N}$; IR: 3323 $(\mathrm{NH}), 1720$ a $1730(\mathrm{C}=\mathrm{O}) ;{ }^{1} \mathrm{H}-\mathrm{NMR}(\mathrm{ppm}): 1,66 \mathrm{~s}, 9 \mathrm{H}\left[\left(\mathrm{CH}_{3}\right)_{3}\right], 2,96 \mathrm{~s} 1 \mathrm{H}(\mathrm{NH}), 3,09-4,33 \mathrm{~m}, 3 \mathrm{H}$ $\left(\mathrm{SCH}_{2} \mathrm{CH}\right), 3,79 \mathrm{~s}, 3 \mathrm{H}\left(\mathrm{OCH}_{3}\right), 5,78 \mathrm{~s}$ a $6,01 \mathrm{~s} 57: 43,1 \mathrm{H}(\mathrm{CH}), 7,13-8,22 \mathrm{~m}, 5 \mathrm{H}$ (H-arom.).

\section{1-(tert-Butoxycarbonyl)-4'-methoxycarbonyl-3-(thiazol-2'-yl) indole (6).}

To a stirred suspension of activated $\mathrm{MnO}_{2}$ [10] (1000 $\left.\mathrm{mg}, 11.5 \mathrm{mmol}\right)$ in a mixture of dry benzene $(10 \mathrm{~mL})$ and pyridine $(0.050 \mathrm{~mL})$ was added a solution of thiazolidine $\mathbf{5}$ ( $400 \mathrm{mg}, 1.10 \mathrm{mmol})$ in dry benzene $(2 \mathrm{~mL})$. The reaction mixture was stirred for 1.5 hour at $55^{\circ} \mathrm{C}$. After cooling the insoluble material was removed by filtration, washed with benzene, the solvent was evaporated and the solid residue crystallized from a mixture of diethylether/hexane. Yield $175 \mathrm{mg}$ (44\%), M.p. 128-130 ${ }^{\circ}$; For $\mathrm{C}_{18} \mathrm{H}_{18} \mathrm{~N}_{2} \mathrm{O}_{4} \mathrm{~S}(359.48)$ calculated: $60.14 \% \mathrm{C}, 5.05 \% \mathrm{H}, 7.79 \% \mathrm{~N}$; found: $60.23 \% \mathrm{C}, 5.21 \% \mathrm{H}, 7.29 \%$ $\mathrm{N}$; IR: $3323(\mathrm{NH}), 1720$ a $1730(\mathrm{C}=\mathrm{O}) ;{ }^{1} \mathrm{H}-\mathrm{NMR}(\mathrm{ppm}): 1,66 \mathrm{~s}, 9 \mathrm{H}\left[\left(\mathrm{CH}_{3}\right)_{3}\right], 3.79 \mathrm{~s}, 3 \mathrm{H}\left(\mathrm{OCH}_{3}\right), 8,10$ $\mathrm{s}, 1 \mathrm{H}(\mathrm{H}-2), 8,25 \mathrm{~s}, 1 \mathrm{H}\left(\mathrm{H}_{-5}{ }^{\prime}\right), 7.13-8,22 \mathrm{~m}, 4 \mathrm{H}$ (H-arom.).

4'-Methoxycarbonyl-3-( thiazol-2'-yl) indole (7).

To a suspension of thiazole $6(150 \mathrm{mg}, 0.42 \mathrm{mmol})$ in dry methanol $(12 \mathrm{~mL})$ was added sodium methoxide $(330 \mathrm{mg}, 6.11 \mathrm{mmol})$ during $5 \mathrm{~min}$. The reaction mixture was poured into cold water (60 $\mathrm{mL})$, extracted with chloroform $(3 \times 10 \mathrm{~mL})$, dried over $\mathrm{Na}_{2} \mathrm{SO}_{4}$, the solvent evaporated and the product crystallized from a mixture of diethylether/hexane. Yield $64 \mathrm{mg}$ (59\%), M.p. 166-168 C; For $\mathrm{C}_{13} \mathrm{H}_{10} \mathrm{~N}_{2} \mathrm{O}_{2} \mathrm{~S}(259.50)$ calculated: $60.17 \% \mathrm{C}, 3.88 \% \mathrm{H}, 10.80 \% \mathrm{~N}$; found: $60.28 \% \mathrm{C}, 3.99 \% \mathrm{H}, 10.95 \%$ $\mathrm{N}$; IR: $3200(\mathrm{NH}), 1720$ a $1730(\mathrm{C}=\mathrm{O}) ;{ }^{1} \mathrm{H}-\mathrm{NMR}(\mathrm{ppm}): 3,79 \mathrm{~s}, 3 \mathrm{H}\left(\mathrm{OCH}_{3}\right), 8.10 \mathrm{~d}, 1 \mathrm{H}(\mathrm{H}-2), \mathrm{J}=2,55$ $\mathrm{Hz}, 8,25 \mathrm{~s}, 1 \mathrm{H}\left(\mathrm{H}-5^{\prime}\right), 7.13-8.22 \mathrm{~m}, 4 \mathrm{H}$ (H-arom.), $10,85 \mathrm{~s}, 1 \mathrm{H}(\mathrm{NH}) .{ }^{13} \mathrm{C} \mathrm{NMR}(\mathrm{ppm}): 52,32\left(\mathrm{CH}_{3}\right)$, $113.05,121.66,122.04,123.83,125.50,125.72,127.41,127.58,137.99,147.78$ (C arom.), 162.61 $(\mathrm{C}=\mathrm{N}), 164.75(\mathrm{C}=\mathrm{O}) . \mathrm{MS}, \mathrm{m} / \mathrm{z}(\%),: 258\left(\mathrm{M}^{+}, 100\right), 200(24), 160$ (24), 142 (24), 115 (12), 57 (12).

\section{Camalexin (1).}

To a solution of $\mathrm{NaOH}(22.0 \mathrm{mg}, 5.6 \mathrm{mmol})$ in water $(2 \mathrm{~mL})$ was added a solution of thiazole 7 $(120 \mathrm{mg}, 0.46 \mathrm{mmol})$ in methanol $(2 \mathrm{~mL})$ and the reaction mixture was refluxed for 1 hour. After cooling and evaporation of the methanol, $\mathrm{NaHCO}_{3}(660 \mathrm{mg}, 7.86 \mathrm{mmol})$ was added and the reaction mixture was refluxed for 1 hour. The product separated after cooling and was collected on filter paper and dried. Crystallization from a mixture of diethylether/hexane yielded $10 \mathrm{mg}$ (12\%); M.p. 140-141 
C; For $\mathrm{C}_{11} \mathrm{H}_{8} \mathrm{~N}_{2} \mathrm{~S}(200.10)$ calculated: $66.00 \% \mathrm{C}, 4.00 \% \mathrm{H}, 14.00 \% \mathrm{~N}$; found: $65.80 \% \mathrm{C}, 4.00 \% \mathrm{H}$, $13.50 \% \mathrm{~N}$; IR, ${ }^{1} \mathrm{H}-,{ }^{13} \mathrm{C}-\mathrm{NMR}$ and mass spectra were identical with previously described data for camalexin $[1,3,6]$.

\section{References}

1. Browne, L.M.; Coon, K.L.; Ayer, W.A.; Tewari, J.P. Tetrahedron, 1991, 47, 3909.

2. Tsuji, J.; Jackson, E.; Gage, D.; Hammerschmidt, R.; Somerville, S.C. Plant Physiol., 1992, 98, 1304.

3. Ayer, W.A.; Craw, P.A.; Yn-Ting, M.; Miao S. Tetrahedron, 1992, 48, 2919.

4. Moddy, C.J.; Roffey, J.R.A.; Stephens, M.A.; Stradford I.J. Anti-Cancer Drugs, 1997, 8, 489.

5. Mehta, G.; Dhar, D. N. Synthesis, 1978, 374.

6. Fürstner, A.; Ernst, A. Tetrahedron, 1995, 51, 733.

7. Sakamoto, T.; Kondo, Y.; Takazawa, N.; Yamanaka, H. J. Chem. Soc., Perkin Trans 1, 1996, 1927.

8. Devys, M.; Barbier, M. Phytochemistry, 1991, 30, 389.

9. Zook, M.; Hammerschmidt, R. Plant Physiol., 1997, 113, 463.

10. Hamada, Y.; Shibata, M.; Sugiuri, I.; Kato, S.; Shiori, T. J. Org.Chem., 1987, 52, 1252.

11. Kutschy, P.; Achbergerova, I.; Dzurilla, M.; Tagasugi M. Synlett, 1997, 289.

Sample availability: Samples of compounds $\mathbf{1 , 5}$ and $\mathbf{6}$ are available from the authors.

C 2001 by MDPI (http://www.mdpi.org). Reproduction is permitted for non-commercial purposes 